\title{
Biodegradation of Crude Oil Using Aspergillus species
}

\author{
Mustafa A. Al-Dossary ${ }^{1 *}$, Shaymaa A.Abood ${ }^{2}$ and Hamid T.AL-Saad ${ }^{2}$ \\ 1. Department of Ecology, College of Sciences, University of Basrah, Iraq. \\ 2. Department of Natural Marine Science, College of Marine Science, University of Basrah, Iraq.
}

\begin{abstract}
Biodegradation of crude oil is a process that utilizes the capability of microorganism to degrade toxic pollutant in the environment. In the present study, three fungal species were isolated from the soil contaminated with crude oil in the oil fields in Basrah. The fungal species belongs to the genus Aspergillus, which are A. flavus ,A fumigatus and $A$.versicolar. Their ability to biodegrade crude oil was tested as single isolates for 15 and 30 days of incubation in the mineral salts medium,the results showed that the fungus $A$. flavus was the best, with biodegradation ability reaching $60 \%$ in 15 days and $80 \%$ in 30 days .
\end{abstract}

Keywords:crude oil, fungi, biodegradation.

DOI: $10.7176 / \mathrm{JBAH} / 9-4-09$

\section{Introduction}

Crude oil is one of the most important energetic resources in the world. It is used as raw material in numerous industries, including the refinery-petrochemical industry ,Oil-derived products are also commonly used in many other chemical processes(Brown et al ., 2017 ;Marchand et al., 2017).

crude oil are complex mixture of organic compounds basically of paraffinic, oleifinic and polycyclic aromatic hydrocarbons(Santos etal., 2014). These hydrocarbons are hazardous to the living organisms and are also carcinogenic, mutagenic and potentimmuno-toxicants which constitutes a serious threat to human and animal health(Alrumman et al ., 2015 ; Sajna et al ., 2015).

The problems of soil contamination with petroleum hydrocarbons often result in significant decline in its quality and such soils become not useful for use(Kisic et al ., 2010 ;Azaizeh et al., 2011).

Their removal becomes essential and several physical and chemical methods are available(Mohammadi-Sichani et al., 2017) .

Biodegradation is a process whereby compounds are broken down into smaller constituents or completely broken down into carbon dioxide and minerals by enzymatic ormetabolic processes.(Abdulrazag et al., 2016; Dahanet al., 2017).Biodegradation of oil contaminated soils, which uses the ability of microorganisms to degrade and/or detoxify organic contamination has been established as oneof the efficient, economic, versatile and environmentally sound treatment(Vidali , 2001 ;Clarkson \& Abubakar , 2015).

Microorganisms with specific metabolic capacities have played a significant role in the biodegradation of crude oil and have probably adapted to environments that require treatment(Jussila, 2006 ;Ron\& Rosenberg , 2014).

Fungi are one of the best oil-degrading organisms; various studies have identified many fungal species capable of using crude oil as their sole source of carbon and energy(Viswanath et al .,2008; Shraddha et al ., 2011).However, the rate of biodegradation is influenced by several factors such as the type of microorganisms Physical and environmental factors such as nutrients, soil type, $\mathrm{pH}$, temperature, moisture, oxygen water holding capacity and nutrient limitations (Aharoni et al., 2017; Avishai et al., 2017).This study the efficiency of fungi to degrade crude oil and the effect of time on this process.

\section{Materials and methods}

\subsection{Crude Oil}

Crude oil was supplied by Southern Oil Company (Basra, Iraq). It was transferred to laboratory in dark bottle closed tightly and kept in a cold and dark place until to use. 


\subsection{Sample collection}

The Soil samples from the surface layer $(5-15 \mathrm{~cm})$ were collected from oil fields in Al-Lahis and Zubair Basra, Iraq, and maintained in plastic bags and storedunder refrigeration at $4^{\circ} \mathrm{C}$ until use (Latha \& Kalaivani,2012).

\subsection{Isolation of fungi}

Dilution method Wicklow \& Wittingham ,( 1974 )was used for theisolation of fungi from soil contaminated by crude oil , $10 \mathrm{~g}$ of soil was dissolved in $90 \mathrm{ml}$ of distilled water to attain a dilution of $10^{-1}$ andShake wellby shaker, $1 \mathrm{ml}$ transferred by Sterile pipette to the petridishesand then mixed with oil agar medium (OAM)this medium prepared according to Obire\&Anyanwu, (2009). Then the petridishes incubated in the incubator under $25^{\circ} \mathrm{Cfor} 3$ days or more depending on the rate of growth. Then, different fungal colony were isolated and cultured separately in PDA. Fungal species were examined under light microscope and identified using morphological characters and taxonomical keys .

\subsection{Testing the ability of fungal species to biodegradecrude oil}

mineral salt medium (MSM) were used which contain : $10 \mathrm{~g} \mathrm{Na} \mathrm{Cl}, 0.42 \mathrm{~g} \mathrm{MgSO} 4,0.12 \mathrm{gKCl}, 0.83 \mathrm{gKH} 2 \mathrm{PO} 4,0.42 \mathrm{~g}$ $\mathrm{NaNO} 3,1.25 \mathrm{~g} \mathrm{Na} 2 \mathrm{HPO} 4$ dissolve in $1 \mathrm{~L}$ of distilled water, the $\mathrm{pH}$ was adjusted to 4.5 , then autoclaved at $120^{\circ} \mathrm{C}$ for 20 min. The (MSM) supplemented with $1 \%(\mathrm{v} / \mathrm{v})$ crude oilwas used as carbonsource and energy for the biodegradation. Two agar plugs $1 \mathrm{~cm}^{2}$ from the pure cultures of each fungal isolates were inoculated into MSM medium $(100 \mathrm{ml} / 250 \mathrm{ml}$ Erlenmeyer flask)containing sterile crude oil 1\% (v/v) as a sole source of carbon and energy.All flasks were Incubated with constant shaking about $120 \mathrm{rpm}$ for tow periods 15 and 30 days at $25^{\circ} \mathrm{C}$.Control flasks had no organism were incubated at same condition.

\subsection{Crude oil extraction}

After the end of the incubation period, fungal activities were stopped by adding $1 \% 1 \mathrm{~N} \mathrm{HCl}$ for the extraction of crude oil. Extraction of crude oil from the liquid medium was done by following the method of Mittal \& Singh, (2009),with some adjustments. The leachate was transferred to separating funnel then $80 \mathrm{ml}$ of Petroleum ether andAcetone 1:1 was added to it, the funnel was shacked well several times for (5-10) minutes with the opening of valve to exit the gases and left to settle downuntil two layer were formed . The upper layer represent theoil hydrocarbonsand the lower represent the (water +Acetone ), the upper layer was taken and passed through colum containing glass wool and sodium sulfate anhydrous to remove the residual water. The solvent was vaporized overnight. This procedure carried out under same condition on the control flask. The percentage degradation of the crude oil was then calculated gravimetrically according to Oudot (1984).

Degradation $\%=\frac{m g \text { of } \text { crud oil control }- \text { mg of crud oil test }}{m g \text { of crud oil control }} * 100$

The descending from the separating column stored in closed sterile container until analysis by Spectrofluorometer.

\subsection{Statisticalanalysis}

Analysis Of Variance (One- way ANOVA) was applied by Minitab ver.16

software and Relative Least Significant Differences (RLSD) values were calculatedto identify the fungal degradation significant differences the design used was complete random design.

\section{Results}

\subsection{Identification of fungal species}

Three fungal species were isolated from contaminated soil in this study, all isolates were showed potentials for hydrocarbon biodegradation and identified as Aspergillus flavus, A fumigatus and A versicolar .

\subsection{Crude oil biodegradation}

All of the fungal species showed a good growth in the (MSM) medium. The biomass of the fungal species increased over the time and varied between the three species,also the fungal species transformed the form of crude oil from a liquid and luminous layer into semi-solid and non-shiny parts. The results showed that the species $A$. flavus gave the best degradation abilityin 15 days and in the 30 days table1.

ANOVA test- showed that there were no significant differences $(p>0.05)$ between the three fungi in the mean concentrations of total petroleumhydrocarbons (TPH) remaining in salt medium after 15 days of incubation, while there were significant differences $(p<0.01)$ between the three fungi in the mean concentrations of total petroleum hydrocarbons (TPH) remaining in the (MSM) medium after 30 days of incubation, also there were significant differences $(\mathrm{p}<0.01)$ in the mean concentrations of total petroleumhydrocarbons $(\mathrm{TPH})$ in the (MSM) 
mediumbetween 15 and 30 days of incubation.

Table1.Mean concentrations of total petroleum hydrocarbons (TPH) andthe percentage of biodegradation of fungal species inLiquid Medium for 15 and 30 days of incubation

\begin{tabular}{|l|l|l|l|l|}
\hline Species & TPH $\mu \mathrm{g} / \mathrm{L}$ after 15 days & Degradation\% & TPH $\mu \mathrm{g} / \mathrm{L}$ after 30 days & Degradation $\%$ \\
\hline A. flavus & $1.32^{\mathrm{a}}$ & $60 \%$ & $0.94^{\mathrm{a}}$ & $80 \%$ \\
\hline A. fumigatus & $1.93^{\mathrm{a}}$ & $36 \%$ & $1.36^{\mathrm{a}}$ & $62 \%$ \\
\hline A. versicolar & $2.11^{\mathrm{a}}$ & $25 \%$ & $1.73^{\mathrm{b}}$ & $51 \%$ \\
\hline Control & 2.4 & - & 2.2 & - \\
\hline RLSD & 1.02 & - & 0.5 & - \\
\hline
\end{tabular}

The similar letter means no difference and the different letter means there is differences between them.

AndANOVA test- one way showed thatthere was also a significant difference in the percentage of biodegradation of crude oil between 15 and 30 days of incubation figure 1.

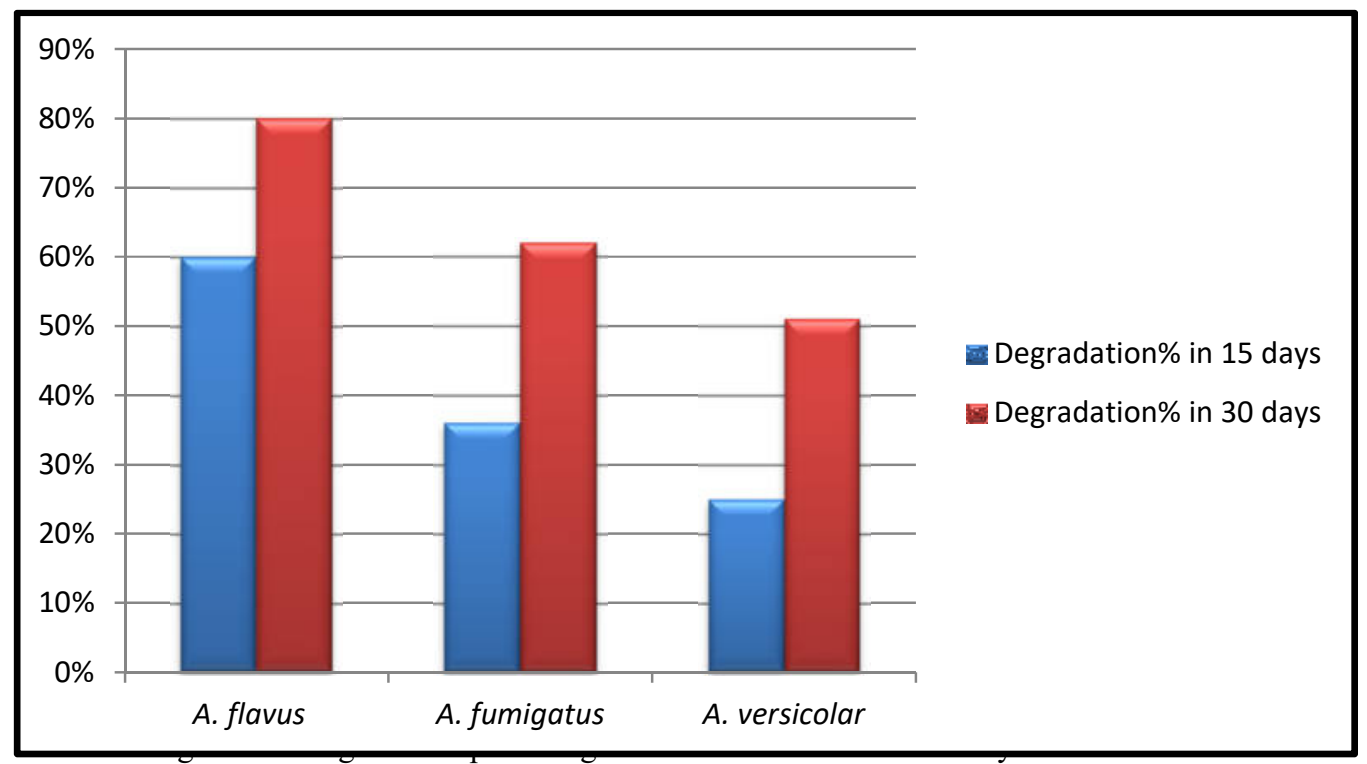

\section{DISCUSSION}

Allthe fungal species which isolated during this study were belonging to the genus Aspergillus, this species is widespread and isolated from all environments and it is commonly found in warm regions, and has the ability to produce large numbers of reproductive units which spread easily in air and soil(Sabah et al. , 2016).Also the widespread prevalence of these species may be due to their various enzymatic capacities (Sharaddah et al., 2011).In addition to the found that some of these species have the ability to produce enzymes such as Cytochrome P-450 monooxygenase and Lignin \&Manganese Peroxides (Durairaj et al ., 2016 ). These fungi have been reported as hydrocarbon bio-degraders isolated from soil(April et al.,2000).Isolated of fungal species from contaminated soil refer to the adaptation of these fungal strains to petroleum compounds and the ability to degrade a wide range to these compounds(Al- Jawhari , 2014 ;Burghal et al ., 2016).

Their ability to biodegrade crude oil, A. flavus gave the highest ability to biodegrade crude oil during 15 and 30 days andthe percentage of biodegradation was $60 \%$ and $80 \%$ respectively during the incubation periods .This may be due to the fact that it has an active and efficient enzymatic system and its high ability to consume petroleum compounds. Several studies have demonstrated the possibility of this species to secret of more than one type of enzymes to biodegrade the different fraction of crude oil, as well as its ability to grow in various difficult environmental conditions and its ability to grow in different environments and the exploitation of different resource 
for growth(Fredrick et al., 2012 ;Mohsenzadeh et al., 2012).The species A.fumigatusand A versicolar showed less ability for crude oil biodegradation, this may be due to the weakness of their enzymatic ability to analyze various components of crude oilwhich led to a decline in their ability to show a result similar to the first fungus.Or they may need more time to degrade crude oil better(Clemente et al., 2001; Diana et al., 2011).The incubation period had a significant role in the processof biodegradation, the results after the incubation period 30 dayswere better in the three species, this is because the fungal mycelium were in attachment for a longer period with crude oil and this enables it to degrade hydrocarbons into simpler compounds and use it as a source for carbon and energy(Nyer et al., 2002; Chiguet al., 2010).

\section{Conclusion}

The results of this study appeared that the isolated fungi showeda good biodegradation efficiency and the species Aspergillus flavus was the best one, also the results showed that the time play an important time on the biodegradation process, in which the percentage of biodegradation increased with time.

\section{Acknowledgement}

We thank every person help us in our work, and help to complete it in this form.

\section{References}

Abdulrazag, Y.; Zekri, A. and Omar, C. (2016).Effect of temperature on biodegradation of crude oil. J. Annals. Agric. Sci., 61(1): 145-154.

Aharoni, I.; Siebner, H.and Dahan, O. (2017). Application of vadose-zone monitoring system for real-time characterization of leachate percolation in and under a municipal landfill. Waste Manage., 67:203-213.

Al-Jawhari, I.F.H.(2014).Ability of some soil fungi in biodegradation of petroleum hydrocarbon. J. App. Environ. Microb.,2 (2) : 46-52.

Alrumman, S.A.; Dominic B.Standing , D.B. and Paton G.I. (2015).Effects of hydrocarbon contamination on soil microbial community and enzyme activity.J. King Saud Univer. Sci. 27(1): 31-41.

April, T.M.; Foght, J.M. and Currah, R.S. (2000). Hydrocarbon degrading filamentous fungi isolated from flare pit soils in northern and western Canada. Can. J. Microb., 46(1):38-49.

Avishai, L.; Siebner, H.; Dahan, O. and Ronen, Z. ( 2017). Using the naturalbiodegradation potential of shallow soils for In-situ remediation of deep vadose zone and groundwater. J. Hazard. Mater., 324:398-405.

Azaizeh, H.; Castro, P.M.L. and Kidd, P. (2011).Biodegradation of organic xenobiotic pollutants in the rhizosphere. Org. Xenobio. Plants, 8:191-215.

Brown, D.M.;Bonte, M.; Gill, R.; Dawick, J. and Boogaard, P.J. (2017).Heavy hydrocarbon fate and transport in the environment.Quarterly J. Engin. Geo. Hydrogeo., 50:333-346.

Burghal,A. A.; Abu-Mejdad, N. M.J. and Al-Tamimi, W. H. (2016).Mycodegradation of crude oil by fungal species isolated from petroleum contaminated soil.Int.J. Innov.Rese.Sci.Engin.Technol. 5:1517-1524.

Chigu, L. ;Hirosue,S.; Nakamura,C;Teramoto,H.; Ichinose,H. and Wariishi, H. (2010) .Cytochrome P450 monooxygenases involved in anthracene metabolism by the white rot basidiomycete phanerochaete.Appl. Microb.Biotechnol., 87(5):1907-1916.

Clarkson, M.A. and Abubakar, S.I. (2015) Bioremediation and biodegradationof hydrocarbon contaminated soils. IOSR J. Environ. Sci., 9(11):38-45.

Clemente,A.R.; Anazawa,T.A. and Durrant,L.R.(2001). Biodegradation of polycyclic aromatic hydrocarbons by soil fungi. Braz. J. Microb., 32:1-9.

Dahan, O.; Katz, I.; Avishai, L. and Ronen, Z.( 2017). Transport and degradation of perchlorate in deep vadose zone: implications from direct observations during bioremediation treatment. Hydrol. Earth Syst. Sci., 21:40114020 .

Durairaj, P.; Hur, J. and Yun, H. (2016). Versatile biocatalysis of fungal cytochrome P450 monooxygenases. Microb.Cell Fact., 15:125-139.

Fredrick, H.; Enontiemonria, E.F.; Cybil, O. and Gbenga, T. (2012). The effect of pseudomonas 
aeroginosaandAspergillusnigeron the bioremediation of raw and treated crude oil polluted water. Int. J. Sci. Technol. 2:345-352.

Kisic, L.; Jurisic, A.; Durn, G.; Mesic, H. and Mesic, S. (2010). Effects of hydrocarbons on temporal changes in soil and crops.Afri.J. agri. Rese. 5(14):1821-1829 .

Latha, R. and Kalaivani, R. (2012).Bacterial degradation of crude oil gravimetric analysis.Pel.Rese. Lib. $3(5): 2789$ -2795 .

Marchand, C. ;St-Arnaud, M.;Hogland, W.; Bell, T.H.andHijri, M.(2017). Petroleum biodegradation capacity of bacteria and fungi isolated from petroleum-contaminatedsoil.Int.Biodet. Biodeg.,116:48-57.

Mittal, A. and Singh, P. (2009). Isolation of hydrocarbon degrading bacteria from soils contaminated with crude oil spills. Indi. J. Exp. Bio., 47:760 - 765.

Mohammadi-Sichani, M.M.; Assadi1, M.M.; Farazmand, A.; Kianirad, M.; Ahadi, A.M. and Ghahderijani,H.H. (2017). Bioremediation of soil contaminated crude oil by Agaricomycetes.J. Environ .Health Sci. Engin., 15:1- 8.

Mohsenzadeh, F ; Rad, A.C. and Akbari, M.(2012). Evaluation of oil removal efficiency and enzymatic activity in some fungal strains for bioremediation of petroleum-polluted soils.Irani. J. Environ. Healt. Sci. Engin.,9:26-34.

Nyer, E.K.; Payne, F.and Suthersan, S.(2002).Environment vs.bacteria or let's play name that bacteria. Grou. Wat. Monit.Remed.,23:36-45.

Obire, O. and Anyanwu, E.C. (2009).Impact concentrations of crude oil on fungal populations of soil and rivers. Sci.Tech.,2: 1735-1472.

Oudot, J. (1984). Rates of microbial degradation of petroleum compounds as determined by computerized capillary gas chromatography and computerized mass spectrometry. Mar. Environ. Rese., 13: 277 - 302.

Ron, E. Z. and Rosenberg, E.; (2014). Enhanced bioremediation of oil spills in the sea, Environ. Biotech., 27: 191194.

Sabah, G.; Jatau , E. and Whong, C. (2016) . Assessment of biodegradation ability of Aspergillus niger isolated from mechanic workshops soil on refinery effluent and petroleum hydrocarbons .Int. J. Sci. Rese. Pub.6 (3) : 381 389.

Sajna, K.V.; Sukumaran, R.K.; Gottumukkala, L.d. and Pandey, A. (2015). Crude oil biodegradation aided by biosurfactants from pseudozyma sp. Nii 08165 Or Its Culture Broth. J. Bioresour. Technol., 191:133-139.

Santos, R. G.; Loh, W.; Bannwart, A. C. and Trevisan, O. V.; (2014).An overview of heavy oil properties and its recovery and transportation methods, Brazil. J. Chem. Engin., 31(3): 571-590.

Shraddha, R.; Shekher, S.; Sehgal, M.; Kamthania, and A. Kumar, A. (2011).Laccase: microbial sources, production, purification, and potential biotechnological applications, Enzy. Rese., 2011:11pp.

Vidali, M. (2001).Bioremediation.Anoverview.Pure. Appl. Chem., 73(1):1163-1172.

Wicklow, D.T. and Wittingham, C. (1974).Soil micro fungal changes among the profiles of disturbed conifer hard wood forest. Ecology, 55:3-16. 